Available online at http://proceedings.sriweb.org

The 1st International Conference on Sciences and Arts (ICMSA 2017)

$$
3 \text { مايو } 2017 \text { - اربئتمر الدولي الاول للعلوم والاداب - العراق }
$$

\title{
The bactericidal activity of Magnetic water on Multi Drug Resistance [ MDR] Pseudomonas aeruginosa Resistance Colistin from clinical and environmental sources and effect on Biofilm
}

\author{
Khalid Hadi Mahdi ${ }^{\mathrm{a}}$ \\ Hanaa Salih Sabab ${ }^{b}$ \\ Nebras Rada Mohammed \\ Mohammad Mahdi Jawad ${ }^{d}$ \\ ${ }^{\mathbf{a}, \mathbf{b}}$ College of Education-Ibn Al Haitham- Baghdad University . \\ ${ }^{\mathbf{c}, \mathbf{d}} \mathrm{Ph}$.D.Studant College of Science - Al- Mustansiriya University .
}

\begin{abstract}
This study was conducted in order to determine the impact of Magnetic water on MDR P.aeruginosa resistance colistin by exposing them to Magnetic water by use several of method by Team work [Staff] including by using tubes and agar method with $5,10 \mathrm{ml}$ in tube method and with 1, 2, $0.8,0.5 \mathrm{ml}$ in Agar method .It was obtained that after exposure to Magnetic water less than the number of cells of bacteria and increase the percentage of killing of P.aeruginosa, With decrease the time and the reason is when you increase the
\end{abstract}




\section{Global Proceedings Repository \\ American Research Foundation}

ISSN 2476-017X

Available online at http://proceedings.sriweb.org

time that magnetic water loses its magnetization property and thus reducing the precentage of killing. Since the magnetic water after 24 hours loses magnetization property, compared with control [without exposure to Magnetic water] .As for the ability to form biofilm after exposure to Magnetic water has led to the loss of biofilm formation, where it lost after the disclosure using the dye Congo Red this property .

It was also study the feasibility of MDR P.aeruginosa resistance Colistin to form biofilm before and after exposure to Magnetic water, were observed that P.aeruginosa resistance Colistin exposed to Magnetic water after it had lost the ability to form biofilm compared to the pre-exposed to Magnetic water [control].

Keywords: P.aeruginosa, Magnetic water, Biofilm .

\section{Introduction}

Pseudomonas aeruginosa is gram negative bacteria , causing many diseases in the human body, including wounds infection ,burns infection, eye infection, skin infections, urinary tract infection ,middle ear infections and bacteremia, causing disease in many people who suffer from HIV disease and people living with AIDS ,they are one of the most important bacterial species that cause what is known as Nosocomial infection [1]. P. aeruginosa has become an important agent of infection, especially in patients with compromised host defense mechanisms, It is a frequent cause of nosocomial infections such as urinary tract infections [UTIs], pneumonia, and bacteremia. Pseudomonal infections are risky and can be life threatening. It is a major cause of hospital-acquired infections [nosocomial infections], and it is difficult to eradicate due to its resistance to most antimicrobial agents . In most cases of infection, the integrity of a physical barrier to infection [eg. mucous membrane, skin] is lost or an underlying immune deficiency is present. In addition to its pathogenicity, this bacterium has minimal nutritional requirements and can tolerate a wide variety of physical conditions [2]..

The importance of $P$. aeruginosa as an opportunistic pathogen relies in its ability to activate useful phenotypes under environmental stress and to persist in adverse conditions such as the presence of antibiotic or antiseptic substances[3]. Biofilm causes numerous chronic infections, such as chronic osteomyelitis ,chronic cystitis, chronic prostatitis, chronic otitis media, chronic pneumonia, in patients with cystic fibrosis in addition, biofilm also causes various infections of biomaterial used in medicine, such as infections associated with the use of intravascular and urethral catheters infections of orthopedic devices contact lenses prosthetic heart valves vocal cord prosthesis [4]. P. aeruginosa considered to be dangerous and dreaded pathogen for its resistance to antibiotics [5]. Its natural resistance to antibiotics is due to the permeability barrier afforded by its outer membrane LPS. In addition P.aeruginosa has antibiotic resistance plasmids [6]. Also its ability to form biofilm on surfaces makes the cells impervious to therapeutic concentrations antibiotics Because 
ISSN 2476-017X

Available online at http://proceedings.sriweb.org

P.aeruginosa natural habitat is the soil [which can live in association with the bacilli, actinomycetes and molds] it has developed resistance to a variety of their naturally occurring antibiotics [7].

The reason for the difficulty of treating injuries to these bacteria to resist many of the antimicrobials, like : B-lactam, Macrolides, like as well as high resistance to Flouroquinolones ,making it one of the most dangerous pathogen and most of the injured human [8].more dangerous resistance to polymyxin , Colistin [polymyxin E] A group of polypeptide antibiotics have been used extensively world wide in topical and ophthalmic solutions for decades two forms of Colistin are commercially available, Colistinsulfate and Colistimethate sodium, that binds with the anionic lipopolysaccharide molecules by displacing calcium and magnesium from outer cell membrane of gram negative bacteria , leading to permeability changes in the cell envelope, leakage of cell contents and cell death [9]. Polymyxins -resistant P.aeruginosa that alterations of the outer membrane of the cell [reduction LPS, reduced levels of specific outer membrane proteins, reduction in cell develop $\mathrm{Mg}^{+2}$ and $\mathrm{Ca}^{+2}$ contents, and lipid alterations are related to the development of resistance [10].

The effects of electromagnetic fields on "smaller" biological objects started to be investigated. The objects studied were cells ,tissues and living organisms ,bacteria are good experimental subjects to evaluate how such prokaryote unicellular microorganisms may respond to electromagnetic fields Because of the nature of microorganisms which makes them suitable for use into areas. Such as basic molecular and cellular biology. They are simpler than plants and animals, both genetically and biochemically, they reproduce rapidly so that large numbers of organisms, with the same genetic composition, can be easily grown [11].

Magnetic water It is a modern technology using devices called magnetic devices These devices make a very intense concentration of magnetic field through the tube wall to reach water and contribute to deal with it ,Magnetic water treatment (also known as anti-scale magnetic treatment or AMT) is a controversial method of supposedly reducing the effects of hard water by passing it through a magnetic field, as a non-chemical alternative to water softening [12].

\section{Materials and methods}

\section{Bacterial isolates :}

A total of 50 MDR $P$.aeruginosa isolates were collected from several samples (abscess and wound , burns , Sputum, blood, urinary tract catheter, urine ,acne .... ) from patients who were admitted to Baghdad hospitals in 2015-2016, and from water in Baghdad .These isolates were identified by conventional biochemical reactions according to the criteria established by [13]. The isolates were inoculated a Nutrient agar plate. The results were read after 24 and $48 \mathrm{~h}$ of incubation at $37^{\circ} \mathrm{C}$. And antibiotic sensitivity was done to different antibiotic them Polymyxins B ,Colistin E , The isolates of P.aeruginosa were inoculated on Muller Hinton Agar plate. and identified by use Vietik2- GN for confirmation . 
Available online at http://proceedings.sriweb.org

\section{Detection of Biofilm Formation :}

It was prepared according to [14]. By use Congo red test, Also [15] have described method for screening of biofilm formation. Plates were inoculated by pure single isolated colony and incubated aerobically for $24-48 \mathrm{hr}$. at $37 \mathrm{C}^{\circ}$. Positive result was indicated by black colonies with a dry crystalline consistency. Weak slime producers usually remained pink, though occasional darkening at the centers of colonies. A darkening of the colonies with the absence of a dry crystalline colonial morphology indicated an indeterminate result , this method used for detection of biofilm formation after and befor exposure P.aeruginosa to Magnetic water .

\section{Effect of Magnetic water on MDR P.aeruginosa resistance Colistin:}

The Magnetic water preparation inside Department of Physics - College of Education-Ibn Al Haitham . and so exposing distilled water to the intensity of a magnetic field of 350 gauss for one hour, after which the surface tension as an indicator of the expense of having become magnetized water. Then magnetized water was used to determine their effect on bacteria and designed both ways by the work team. As illustrated below :

\section{1-Tube Method :}

It has this way by the Team work, where bacteria culturing on the Pseudomonas Agar, then after $18-24$ hours at a temperature $37^{\circ} \mathrm{c}$ until access MDR P.aeruginosa to the stationary phase, I attended a test tube containing $5 \mathrm{~mL}$ of Nutrient broth and placed with $5 \mathrm{ml}$ of Magnetic water and test tubes Other position with $10 \mathrm{ml}$ of magnetic water and various Magnetic hours 1, 2 and 3 hour. Then put $5 \mathrm{ml}$ and $10 \mathrm{ml}$ of Magnetic water and placed with the Nutrient broth, after that injected with bacteria. some of them left with Magnetic water for 1 hour, another 2 hours, 3 hours and 24 hours . after that planted on Nutrient agar and incubated for $24 \mathrm{hr}$. at tempreature $37^{\circ} \mathrm{c}$. counting the number of viable cells and precentage of killing after exposure to Magnetic water in different time ,compared with Control (without exposure to Magnetic water) .

percentage of killing of P.aeruginosa calculated according to the following equation below : 


\section{Global Proceedings Repository \\ American Research Foundation}

ISSN 2476-017X

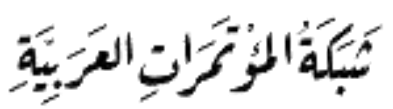

http://arab.kmshare.net/

Available online at http://proceedings.sriweb.org

\section{Control - treated}

\section{Killing of percentage $\%=$ \\ Control}

\section{2-Agar Method :}

It has this way by the team work, where bacteria culturing on the Pseudomonas Agar, then after $18-24$ hours at a temperature $37^{\circ} \mathrm{c}$ until access MDR P.aeruginosa to the stationary phase, I attended a Nutrient agar and Pseudomonas agar planted with P.aeruginosa incubated for $24 \mathrm{hr}$. at tempreature $37^{\circ} \mathrm{C}$.

Attended the Nutrient agar and Pseudomonas agar after his release from Autoclave, left to cool before it freezes and mixing with $\mathrm{g} 0.8 \mathrm{ml}$ and $0.5 \mathrm{ml}$ of Magnetic water, then culturing with P.aeruginosa, incubation for 24 hours with a temperature of $37^{\circ} \mathrm{C}$. Counting the number of viable cells and precentage of killing after exposure to Magnetic water, compared with Control [without exposure to Magnetic water] .

percentage of killing of MDR P.aeruginosa Calculated according to the following equation below :

\section{Control - treated}

\section{Killing of percentage $\%$}

$* 100$

\section{Control}

\section{Results and Discussion \\ Effect of Magnetic water on MDR P.aeruginosa resistance Colistin :}

The effects of magnetic fields on running water, a wide range of biological effects have been induced by applying magnetic fields in both laboratory and clinical experiments. Back in 1982 .researchers discovered the effects of magnetic fields on ion flux through cell membranes.e.g. the increased flow or movement of calcium ions within a magnetic field led doctors to place magnets above and below bone fractures to speed up calcium accumulation at the break thus causing the bone to heal faster. Experiments in 1985 confirmed that other 


\section{Global Proceedings Repository \\ American Research Foundation}

ISSN 2476-017X

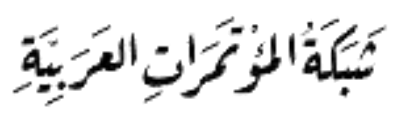

http://arab.kmshare.net/

Available online at http://proceedings.sriweb.org

bodily elements such as sodium, potassium, magnesium, were also effected by this process. addition, we know now that molecular alignment will occur within intense magnetic fields. muscle fiber, membranes, chloroplast, retinal elements of the eyes, and other fibers and macro molecules including nucleic acids have been aligned in an intense magnetic field. Highly oriented structures can result from this which may interact with other biomaterials in your body. magnetic fields could effect the membrane's fluidity or other properties. It only takes a very low intensity magnetic field to effect chemical reactions and these reactions have a definite biological effect on your body [16 ].

The human body is profoundly responsive to electromagnetic fields. MRI [magnetic resonance imaging] is a powerful medical diagnostic technique which uses magnetic fields to distinguish between healthy and diseased tissues. Treatment with pulsed electromagnets [pulsars] has been found highly effective in curing or alleviating conditions such as bone fractures, migraine headaches, insomnia and depression. Pads and mattresses with built-in magnets are used to alleviate insomnia, rheumatic pain, migraines and circulatory problems. Dr. Wolfgang said "Magnetic field therapy is a method that penetrates the whole human body and can treat every organ without chemical side effects"[17 ].

Water is essential for survival ,It has been stated that our existence is "intimately connected with the quality of water available to us, According to F. Batmanghelidj, MD, author of "Your Body's Many Cries for Water", " $25 \%$ of the human body is made up of solid matter while the remaining $75 \%$ is water." Therefore, if our bodies are not continuously supplied with water, our bodies become dehydrated and the vital organs will deteriorate until they are no longer viable for human life [18].

Water also acts as a purifier in our body. If enough water isn't consumed, one is unable to properly flush out their kidneys and/or liver, and the colon is unable to expel bowels properly and completely thus keeping unhealthy toxins in the body, The longer the waste remains in the body, the more time the body has to reabsorb the toxins back into the bloodstream, As a result, the toxins are able to make its way through the human body causing poisoning and spreading infections [19].

Water is the essence of basic survival. Without it, life on Earth would cease to exist. In order to ensure that human life continues to exist, Researchers must do their part in the laboratory to come up with treatment methods to improve the quality of drinking water. When the quality of drinking water is good, human health is also good. [20].

Living water [Magneized water ] is important to hydrate every cell in body. But the water delivered to us from household taps is contaminated with chemicals, industry waste, effluent and garbage. It's also under such pressure that we now learn its life-giving energy is all but destroyed. need water that is not only purified but revitalized to bring it back to something close to the life-giving, nourishing, cleansing element it was designed to be. That is apparently done through magnets. [16 ].

Dr. Klaus Kronenberg is a scientist, original research used magnets in water treatment for industry. "Water is chemically neutral," he said, "but it is one of the best solvents known to man. It has the ability to entrap other substances. In other words, water tends to cluster around every non-water particle, forming conglomerations or complexes. [Raising Youp $\mathrm{Ph}$ ]. 


\section{Global Proceedings Repository \\ American Research Foundation}

ISSN 2476-017X

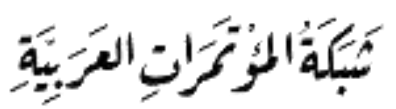

http://arab.kmshare.net/

Available online at http://proceedings.sriweb.org

Magnetized water is truly emerging as one of the most exciting developments in the ongoing battle to protect health. [21 ].

Magnetized water was first used in Russia by three specialists: Drs. G. Gerbenshchikow, I. Shetsov and K. Tovstoles, all three specialists in urology . They had their patients drink bipolar magnetized water. This simple treatment was very effective in breaking up kidney and gall bladder stones into small enough particles to be passed through urine without any pain or danger to the patient. The water also prevented further formation of stones in the kidneys and gallbladder . Soviet physicians have been giving internally magnetized water to patients for over 30 years for digestive, urinary and nervous problems, ailments like mastitis, pains and swellings, painful urination and many other disorders. Because magnetized water is wetter and therefore more penetrating, it furthers better assimilation of the various nutrients and vitamins in the cells [16] .

Table [1]:MDR P.aeruginosa colonies after exposure to Magnetic water, and Precentage of killing by Tube Method :

\begin{tabular}{|c|c|c|c|c|}
\hline Isolates & $\begin{array}{l}\text { Magnetic } \\
\text { [water }[\mathrm{ml}\end{array}$ & [Time [hr. & $\begin{array}{l}\text { Number of colonies of } \\
\text { MDR P.aeruginosa }\end{array}$ & $\begin{array}{c}\text { Killing of percentage } \\
\%\end{array}$ \\
\hline \multirow[t]{2}{*}{ P1 } & \multirow{2}{*}{$\begin{array}{c}5 \mathrm{ml} \\
10 \mathrm{ml}\end{array}$} & 1hr. & [0 [no growth & $100 \%$ \\
\hline & & 1hr. & [0 [no growth & $100 \%$ \\
\hline \multirow[t]{2}{*}{$\mathbf{P 2}$} & \multirow{2}{*}{$\begin{array}{c}5 \mathrm{ml} \\
10 \mathrm{ml}\end{array}$} & $2 \mathrm{hr}$. & 47 & $81.2 \%$ \\
\hline & & $2 \mathrm{hr}$. & 50 & $80 \%$ \\
\hline \multirow[t]{2}{*}{ P3 } & \multirow{2}{*}{$\begin{array}{l}5 \mathrm{ml} \\
10 \mathrm{ml}\end{array}$} & $3 \mathrm{hr}$. & 60 & $76 \%$ \\
\hline & & $3 \mathrm{hr}$. & 100 & $60 \%$ \\
\hline \multirow[t]{2}{*}{ P4 } & $10 \mathrm{ml}$ & 24hr. & 79 & $68.4 \%$ \\
\hline & & & Control $=250$ colonies & \\
\hline
\end{tabular}




\section{Global Proceedings Repository \\ American Research Foundation}

ISSN 2476-017X

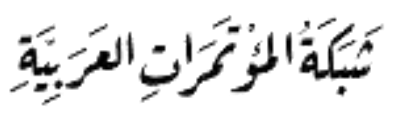

http://arab.kmshare.net/

Available online at http://proceedings.sriweb.org

P1, P2 ,P3, P4 Means MDR P.aeruginosa exposure Magnetic water in different time.

Table [2]:MDR P.aeruginosa colonies after exposure to Magnetic water, and Precentage of killing by Agar Method :

\begin{tabular}{|c|c|c|c|}
\hline Isolates & $\begin{array}{c}\text { Magnetic water } \\
{[[\mathrm{ml}}\end{array}$ & $\begin{array}{c}\text { Number of colonies of } \\
\text { MIDR P.aeruginos } a\end{array}$ & $\begin{array}{c}\text { Killing of percentage } \\
\%\end{array}$ \\
\hline $\mathbf{P 1}$ & $\mathbf{0 . 5} \mathrm{ml}$ & No growth & $100 \%$ \\
\hline $\mathbf{P 2}$ & $\mathbf{0 . 8} \mathrm{ml}$ & No growth & $100 \%$ \\
\hline $\mathbf{P 3}$ & $\mathbf{1 m l}$ & No growth & $100 \%$ \\
\hline $\mathbf{P 4}$ & $\mathbf{2} \mathbf{~ m l}$ & No growth & $100 \%$ \\
\hline & & Control = 250 colonies \\
\hline
\end{tabular}

P1, P2 ,P3, P4 Means MDR P.aeruginosa exposure Magnetic water in different volume . 


\section{Global Proceedings Repository \\ American Research Foundation}

ISSN 2476-017X

Available online at http://proceedings.sriweb.org

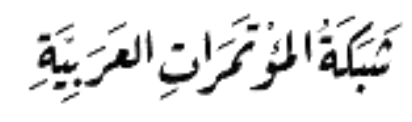

http://arab.kmshare.net/

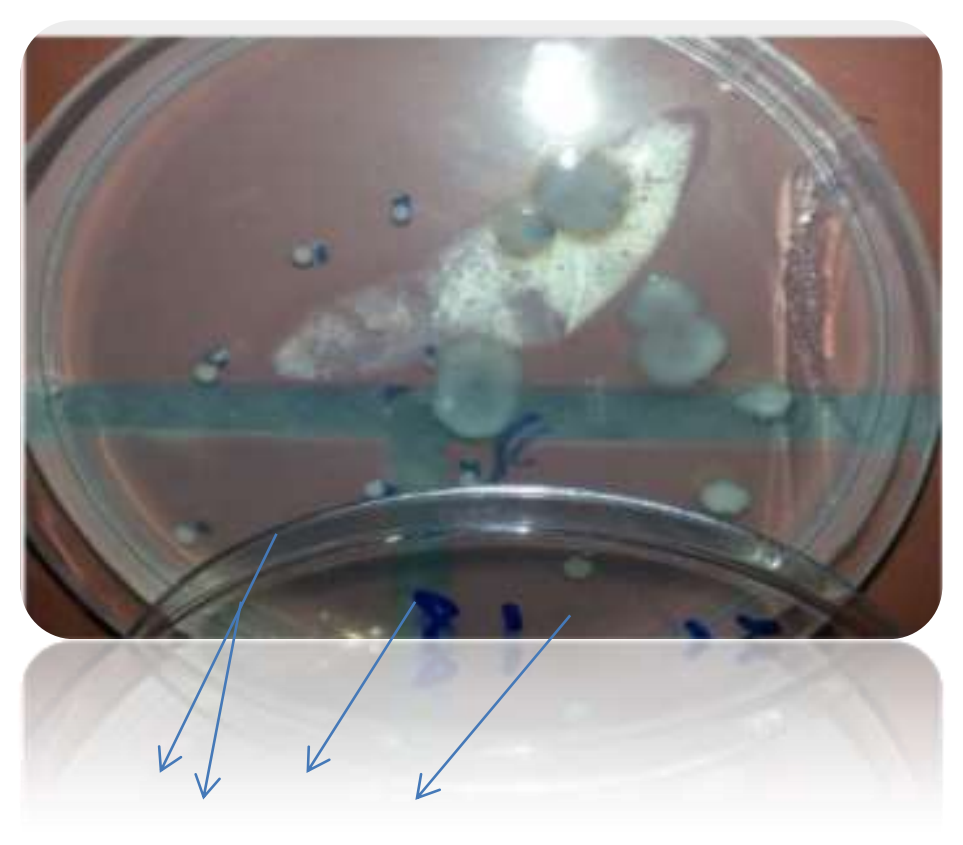

MDR P.aeruginosa after exposure to Magnetic water

\section{Figure [2]: P.aeruginosa exposed to Magnetic water}

In the table [1] the use of the Tube method using magnetic water with $5 \mathrm{ml}, 10 \mathrm{ml}$ and exposing the MDR P.aeruginosa at different times. The results show that the bacteria when exposed to a Magnetic water and less time was more Magnetic effect of water on the bacteria. Where the Precentage of killing of $100 \%$, This indicates that the Magnetic held water feature magnetization, The more time whenever Magnetized water starts losing magnetization property and therefore have a weak effect on killing MDR P.aeruginosa .

As Table [2] shows the Agar method and then mixing the Magnetic water with Agar and different sizes $(1,2,0.5,0.8) \mathrm{ml}$ and the results show that all volume used with Magnetized water in this manner was Precentage of killing where $100 \%$ as a result of the presence of Magnetic water with Agar and stay for a long time and thus did not allow the MDR P.aeruginosa to grow the length of the incubated and by the fact that Magnetic water mixed with Agar where he worked as a disability of bacteria and difficult to grow. Thus, the proportion of very high murder and all the results of the killing of $100 \%$. 
ISSN 2476-017X

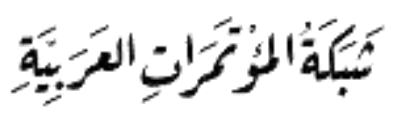

http://arab.kmshare.net/

Available online at http://proceedings. sriweb.org

The vitalizing and healing properties of magnetized water are believed to be intimately tied in with its "memory". Fresh, "virgin" water from a mountain stream is full of vitality especially if it has flowed over volcanic rock which is highly paramagnetic. During its passage through contaminated soil, miles of iron or plastic pipe, and treatment plants where it is exposed to toxic chemicals it loses its vitality. By the time it comes out of the tap it is essentially lifeless. Other researchers suggest that the degradation of our tap water can bring its vitality lower than the vitality of the human body, resulting in feeling drained and tired after a shower or bath[22 ].

regenerate water to its original healthy state by magnetizing it. A water molecule consists of two hydrogen atoms and an oxygen atom. Because of the electron configuration of the molecule the hydrogen atoms tend to attract other water molecules resulting in the formation of clusters which can contain anywhere from four to hundreds of water molecules each. Hungary has shown that these clusters actually have a memory and can remember and carry an imprint of the magnetic energy they have been exposed to either simply from the earth's magnetic field or through flowing over paramagnetic rock. It is the fact that this memory is devastated on the way to the tap which renders our drinking water lifeless[21].

Dr. Viktor Schauberger, have developed units which produce "living water". The units first use violent vortex mixing in a special chamber to eliminate the water's memory of pollutants, chlorine. and then imprint a beneficial magnetic memory on the water before it exits the tap. The units are installed under the sink or on the main water line and should always be situated after any other filters and treatment devices [23 ].

Magnetized water has been found effective in alleviating colds, coughs, bronchitis, all types of fever and more. it helpful in the regularization of women's menses. helpful for tiredness in daily activities. Biophysicist Albert R. Davis, a pioneer in magnet therapy research, wrote in his book "The Magnetic Effect" that he and his co-workers found they could overcome the early afternoon letdown by drinking a glass of magnetized water while relaxing for a few minutes. [16].

Duration of exposure and field strength, gradient, rate of change, and orientation along or perpendicular to flow are variously cited as important to the results [24]. Simon Parsons proposed that the magnetic field reduces the surface charge on small particles, increasing the tendency to coagulate as large particles that stay with the flow rather than depositing as scale [25].

Liu et al [26]. and Coey and Cass demonstrating that magnetic treatment causes water containing minerals to favor formation of a more soluble form of calcium carbonate [aragonite rather than calcite] [27].

Place a glass or plastic container filled with water on the Magnetic Drinking Pad. Leave the container on the pad and add water as needed. Fluids like juice, milk, tea, coffee and liquid type foods can be magnetized the way water is magnetized. Similarly oils, ointments and 


\section{Global Proceedings Repository \\ American Research Foundation}

ISSN 2476-017X

Available online at http://proceedings.sriweb.org

lotions used in ailments like rheumatism or for beauty can be magnetized. Magnetic facial cream is already available commercially. [16 ].

The fact that body consist mainly of water and that all body process are heavily dependent on water has lead to research into the possibility of using magnetized water to promote health and treat disease. that cleaning the teeth with water from a magnetized irrigator can reduce calculus formation by over 60 per cent and improve overall gum health[ 21 ].

Magnetized water is claimed to be energy-building, activating, cleansing and detoxifying. There are resolving bladder problems, recovering quickly from a stroke, alleviating arthritis pain and reducing blood pressure by drinking magnetized water. [23 ].

In his book "Magnets For Your Health" Dr. Louis Donnet, M.D., wrote, "magnetized water can be helpful in weight control, as an adjutant to a correct diet that he has seen over 100 successful cases. Because this water improves metabolic activity, it may be helpful in burning up excessive fatty tissue. Similarly to the way magnetized water dissolves the settled salts on the wall of boilers and radiators, to help unclog the arteries and veins of deposits of cholesterol and salts and normalize the circulatory system. Patents on treating water with magnets appeared successful use of magnets in treating water for irrigation, industry and home use. They cited improvements in taste and faster drying time [16 ].

"Access to safe water is a fundamental human need and, therefore, a basic human right. Contaminated water jeopardizes both the physical and social health of all people. According to medical experts, an individual needs to consume at least 2 liters of water daily for basic survival, If not treated for properly, drinking water can pose a severe health risk for humans. Waterborne Diseases: Waterborne diseases "arise from the contamination of water by human and/or animal body excretions infected by pathogenic viruses or bacteria, which are directly transmitted when the water is consumed or used for food preparations." [28 ].

The effects of the North pole [negative] and South pole [positive] magnetism .North polarity stabilizes, calms and sedates and also reduces pain, infection and inflammation. South polarity, is acid producing, enervating, biologically disorganizing and may accelerate bacteria growth [29].

Magnetized water has also been found useful in the treatment of swimming pool water. that they could reduce the amount of chlorine needed to kill bacteria in a pool by 30 percent by clamping magnets on the water supply line. Dr. Klaus has found that the use of magnetized swimming pool water essentially eliminates the deposits formed where the top surface of the water meets the sides of the pool[30].

the use of magnetized water increased farm yields by anywhere from 5 to 20 per cent. Cows drinking magnetized water produced more milk and were healthier than cows drinking untreated water. Sheep produced more wool and meat, hens laid more eggs and all farm animals survived longer when drinking magnetized water [31 ].

The use of water treated by contact with paramagnetic soil is still in its infancy., agricultural have clearly shown that both the paramagnetic soil itself [used as a fertilizer] and irrigation with paramagnetically treated water increase yields and plant vigour significantly[32].

\section{Detection of biofilm formation}




\section{Global Proceedings Repository \\ American Research Foundation}

ISSN 2476-017X

Available online at http://proceedings.sriweb.org

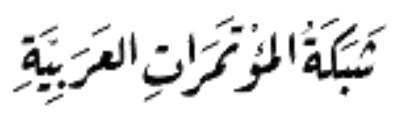

http://arab.kmshare.net/

The results show the ability of bacteria to form biofilm by exposure to Magnetic water an important quality of these bacteria resistant to many antibiotics, as one of the causes of resistance to antibiotics is a composition of biofilm, either after exposure to Magnetic water was found that the bacteria lost recipe composition of biofilm,

Were exposed to magnetic water of different volume and different times, and after the exposure of the magnetic water has been detected for the ability of MDR P.aeruginosa to produce biofilm, where we noticed that the MDR P.aeruginosa had lost the ability to form biofilm after exposure Magnetic water and in all times and in all volume by two methods Tube and Agar method $(0.5,0.8,1,2,5,10) \mathrm{ml}$. This shows that magnetic water is effective in eliminating one of the causes of resistance of bacteria to antibiotics .. not a disposal of biofilm which is important for the bacteria which is one of the means of resistance of bacteria to antibiotics, detergents, disinfectants, antiseptics and other materials.

Represents collection of microorganisms attached to the surface of the material and Mngmrh in the viscous gel outside the cell Extracellular polymeric substances (EPS) [33], and often consist of one type or from several bacterial species interfere with each other and with the environment in which they live [34]

it is the ability of bacteria to form biofilm from a task pathogenic bacteria factors, as the biofilm formation allows the bacteria to escape from the host's defenses and reduce the penetration of antibiotics inter through the membranes, leading to a lack of exposure of bacteria to antibiotics, and then the lack of effectiveness of these antibiotics towards it, as well as protect it from the impact of toxic substances used in sterilizers and disinfectants to kill bacteria $[35,36]$.

The viability of P.aeruginosa adhesion and the formation of a multi-layered on the host tissue and other surfaces and one of the important virulence factors vital membrane

According to [37] showed that 43 isolation (71.7\%) out of 60 isolated productive specific strong sticky layer mediated formation black colonies, while\% 28.3 isolates 17 isolation unproductive class sticky above but were specific to colonies of pink, and the results showed that the isolates were resistant Colstin all of which were produced biofilm

Found [38] that $90 \%$ of the isolates studied colonies gave the black color on the red Congo Red Agar, while $10 \%$ of them gave the colonies of pink, which indicates that it is producing biofilm.

According to [39] Among to $72.7 \%$ of the isolates gave black colonies on the Congo Red Agar and pointed out that the composition of bacterial cells bio-membrane leads to a lack of exposure to antibiotics and then the lack of effectiveness of these antibiotics towards it.

\section{Refrences}

[1] Vianelli ,N.; Giannini, M.B and Quartic , C .[2006]. Resolution of Pseudomonas aueroginosa Outbreak in a haematology unit with the use of disposable sterile water filter . Haematol,J;91[7]:983-985.

[2] -Pollack, M.[ 2000]. Pseudomonas aeruginosa. In: Mandell GL, Bennett JE, Dolin R, eds. Principles and Practice of Infectious Diseases. 5th ed. New York, NY: Churchill Livingstone;:2310-27. 


\section{Global Proceedings Repository \\ American Research Foundation}

ISSN 2476-017X

Available online at http://proceedings.sriweb.org

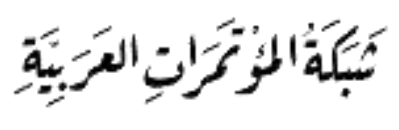

http://arab.kmshare.net/

[3] -Govan,J.R.[2007].Pseudomonas aeruginosa and non fermenters ,Medical Microbiology $.17^{\text {th }}$ ed . Churchill Livingtone Elsevier.

[4] -Singh ,R.; Paul,D and Jain,R.K .[2006]. Biofilms:implicationsin .bioremediation .J. Trends. Microbiol .14:389-397.

[5] -Poole,K .[2005]. Aminoglycoside resistance in Pseudomonas aeruginosa. Antimicrob . agents . Chemother. 49[2]:479-487.

[6] -Gunn,J.S.[2008]. The Salmonella PmrAB regulon : lipopolysaccharide modifications,antimicrobial peptide resistance and more. J. Trends Microb.16:284290.

[7] -Haubler,S.[2008].Pseudomonas Genomics and Molecular Biology Pseudomonas aeruginosa Biofilms $1^{\text {st }}$ Ed, Cornelis P.Caister Academic Press,Norfolk, Uk.

[8] - Lambert,P.A.[2002]. Mechanisms of antibiotic resistance in Pseudomonas aeruginosa . J . Royal. Soc .Med 95: 22-26.

[9] - Falagas, M.E. and Kasiakou, S.K.[2005]. Colistin : The revival of polymyxin for the Management of Multi-drug-Resistant Gram-Negative Bacterial Infections. Clin. Infect. Dis. .editor Louis, D. and saravolatz .

[10]-Denton,M.;Kerr ,K.; Mooney ,L.,et al. [2002].Transmission of Colistin-resistant Pseudomonas aeruginosa between patients attending a pediatric cystic fibrosis Center .Pediatr .Pulmonol. 34: 257-61 .

[11] Ibraheim M.H and Darwish D.B.E [2013]. $50 \mathrm{~Hz}$ Frequency Magnetic Field Effects On Pseudomonas aeruginosa and Bacillus Subtilis Bacteria. IOSR Journal of Applied Physics [IOSR-JAP] e-ISSN: 2278-4861.Volume 5,. PP 49-56.

[12]-Loraine A. Huchler, P.E., MarTech Systems, Inc., Lawrenceville, NJ [2002]. "Nonchemical Water Treatment Systems: Histories, Principles and Literature Review" [PDF]. International Water Conference [IWC], Pittsburgh, PA, USA .

[13]- Forbes.B.A; Sahm.D.F. and Weissfeld A.S. [2007] baily and scotts diagnostic microbiology $.11^{\text {th }}$ edition .Mosby ,Inc. Baltimore, USA. 384-398.

[14]-Freeman, D.J.; Falkiner, F.R. and Keane, C.T.[1989]. New method for detecting slime production by coagulase negative staphylococci. J . Clin. Pathol. 42:872-874

[15]-Mathur,T.; Singhal ,S and Khan ,S. [2006].Adverse effect of Staphylococci slime on in vitro activity of glycopeptides. pn. J. Infect. Dis 58: 353-7.

[16]-RAISING YOUR PH .MAGNETIC WATER. Life Sources, Inc. 5006 Sunrise Blvd.,Ste.101 .Fair Oaks, California 95628916-536-9930.www.life-sources.com. (C) 2003 Life Sources, Inc. All Right Reserve .

[17]-Sherman, R., et al. [1996]. The effect of pulsed electromagnetic fields on classic migraine headaches. International Association for the Study of Pain. 8th World Congress on Pain, August 17-22, Vancouver, BC, Canada. Abstracts, p. 111.

[18]-Routledge, D. and Stewart, D. [1998]. Water: Essential for Existence. Explore Magazine,[Volume 8/Number 5].

[19]-Global Healing Center.[1998-2010]. The Toxins In Our Drinking Water: http://www.globalhealingcenter.com/water-toxins.html .

[20]-Ahmed ,R.[2010]. [Drinking Water Contamination and Its Effects on Human Health . MPHP 429: Introduction to Environmental Health . 4.8.2010 . 


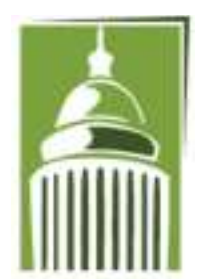

ARF

\section{Global Proceedings Repository \\ American Research Foundation}

ISSN 2476-017X

Available online at http://proceedings.sriweb.org

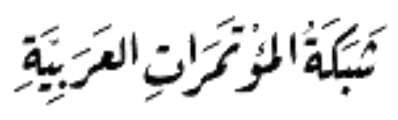

http://arab.kmshare.net/

[21]-Hans R. Larsen, MSc ChE . Magnetized Water: Universal Source of Health?.

[22]-Narvaez, Thomas. Vibrations within water [an interview with Dr. Wolfgang Ludwig]. http://virginwaters.com/virginwaters/vibwitwatbyd.html.

[23]-Virgin Water Limited. Products and Services: Technical Information.

[24]- Chaplin, M. [2011]. "Descaling of Water". Water Structure and Science.London South Bank University. Retrieved 2012-03-26.

[25]- Krauter, P.W.; Harrar, J.E.; Orloff, S.P. and Bahowick, S.M. [1996]. "Test of a Magnetic Device for Amelioration of Scale Formation at Treatment Facility D" Internal Report.Lawrence Livermore National Laboratory. OSTI 567404. Retrieved 2009-12-11.

[26]- Liu, C. Z.; Lin, C. H.; Yeh, M. S.; Chao, Y. M.; Shen, P [2010]. "Surface Modification and Planar Defects of Calcium Carbonates by Magnetic Water Treatment". Nanoscale Research Letters. 5 [12]: 19821991. Bibcode:2010NRL.....5.1982L.doi:10.1007/s11671-010-9736-

5. PMC 29912212. PMID 21170405.

[27]- Coey, JMD; Cass, S [2000]. "Magnetic water treatment" .Journal of Magnetism and Magnetic Materials. 209: 7174. Bibcode:2000JMMM..209...71C.doi:10.1016/S0304-8853[99]00648-4.

[28]-de Kok, T.; Guidotti, T.; Kjellstrom, T. and Yassi, A. [2001] Basic Environmental Health. New York: World Health Organization .

[29]-Bonlie, Dean. [ 1997] Magnetism: The two-faced healer. Alive, \#179, .pp. 54-55.

[30]-Kronenberg, Klaus J.[1993]. Magnetized II: More alluring facts about treating water with magnets. Aqua Magazine. 20-23.

[31]-Nafalski, Andrzej, et al [1994]. Magnetic water treatment: Attempts of objective explanation. International Conference ELMECO '94. Electromagn. Devices Processes Environ. Prot., Proceedings.pp. 161-65.

[32]-Callahan, Philip S. [1995]. Paramagnetism: Rediscovering nature's secret force of growth. Acres U.S.A., Metairie, LA,.

[33]- Donlan, R.M.and Costerton ,J.W.[2002]. Biofilms: survival mechanisms of clinically relevant microorganisms .Clinical microbiology Rev.15[2]:167-193.

[34]- Ali, O.A.[2012] . Prevention of proteus mirabilis Biofilm by Surfactant solution . Egypt . Acad .J . Biology . Sci . 4[1]:1-8 .

[35]-Hall-Stoodley ,L.; Costerton ,J.W. and Stoodley,P. [2004]."Bacterial biofilms: from the natural environment to infectious diseases J.Nat.Rev.Microb.2[2]:95-108 .

[36].Stepanovic'.S.;Vukovic',D.;Hola,V.;DiBonaventura,G.;Djukic',S.;Cirkovic',I.andRu zicka,F.[2007].Quantification of biofilm in microtiter plates : overview of testing conditions and practical recommendations for assessment of biofilm production by Staphylococci .J.APMIS .115:891-899.

[37]- AL-Aoubaydy N.R.M [2015]. Molecular detection and Gene expression of Efflux Pumps in Multidrug resistance Pseudomonas aeruginosa .M.S.C.. AlMustansiriyah University/college of Science/department of Biology/Microbiology. 


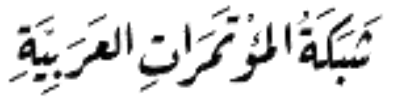

http://arab.kmshare.net/

Available online at http://proceedings.sriweb.org

[38]-Rewatkar, A.R.and Wadher , B. J .[2013].Staphylococcus aureus and Pseudomonas aeruginosa Bioflim formation methods .J .pharma. .bio. sci. 8[5]:3640.

[39]-Nagaveni , S.; Rajeshwari , H.; Ajay , K. and Kelmani , C.R.[2010]. Evaluation of Bioflim foming ability of the multidrug resistance Pseudomonas aeruginosa ..Biol. Internat .J .sci. .5[4]:563-566. 